\title{
AFFORDANCES DOS MATERIAIS COMO INDUTORES DE EQUIVOCOS DURANTE EXPERIMENTOS PARA O ENSINO DE FÍSICA
}

\author{
Carlos Eduardo Laburú* ${ }^{* 1}$ \\ Osmar Henrique Moura da Silva** \\ Andreia de Freitas Zômpero***
}

RESUMO: O artigo revisita o conceito de affordance e dirige sua leitura para o contexto das atividades experimentais para o ensino de física. O conceito de affordance é tratado segundo o significado de reconhecimento imediato que estudantes atribuem a um material ou instrumento em interação com eles, o que gera frequentes comportamentos incorretos. Os equívocos são devidos a inerentes características morfológicas de construção dos objetos que tendem a gerar interpretações semióticas incorretas de como usá-los. O trabalho apresenta ocorrências de enganos cometidos frequentemente por licenciandos de física quando em processo de aprendizagem de experimentos voltados para o ensino médio. O estudo mostra que os tipos singulares de equívocos cometidos podem ser explicados à luz do conceito de affordances.

Palavras-chave: Educação científica. Affordances. Semiótica. Experimentos.

AFFORDANCES DE LOS MATERIALES COMO INDUCTORES DE EQUIVOCOS DURANTE EXPERIMENTOS PARA LA ENSEÑANZA DE LA FÍSICA

RESUMEN: El artículo revisita el concepto de affordance y dirige su lectura al contexto de las actividades experimentales para la enseñanza de la Física. El concepto de affordance es tratado segundo el significado de reconocimiento inmediato que estudiantes atribuyen a un material o instrumento en interacciones con ellos, lo que genera frecuentes comportamientos incorrectos. Los equívocos se deben a inherentes características morfológicas de construcción de los objetos que tienden a generar interpretaciones semióticas incorrectas de cómo usarlos. Este trabajo presenta ocurrencias de engaños cometidos frecuentemente por licenciandos de la física cuando en proceso de aprendizaje de experimentos para la Secundaria. El estudio muestra que los tipos singulares de equívocos cometidos pueden ser explicados bajo la luz del concepto de affordances.

Palabras clave: Educación científica. Affordances. Semiótica. Experimentos.
* Professor do Departamento de Física, Universidade Estadual de Londrina (UEL), Doutor

Faculdade de Educação (USP). Londrina, PR - Brasil. E-mail: <laburu@uel.br>.

* *Físico do Departamento de Física, Universidade Estadual de Londrina (UEL), Doutor Faculdade de Ciências (UNESP) Bauru. Londrina, PR - Brasil.

E-mail: <osmarh@uel.br>.

* * Professora da Universidade Norte do Paraná (UNOPAR), Doutora em Ensino de Ciências e Educação

Matemática pela Universidade Estadual de Londrina (UEL) Londrina, PR - Brasil. E-mail: < andzomp@yahoo.com.br >. 


\section{AFFORDANCES OF THE OBJECTS AS ERRORS INDUCTORS DURING PHYSICS TEACHING EXPERIMENTS}

ABSTRACT: The article revisits the affordances concept and directs its reading to the context of experimental activities on physics teaching. Here, affordances concept is interpreted as the immediate meaning that students attribute to a material or tool when interacting with it, and that association generates frequent incorrect recognition behaviours. These errors are due to objects construction's inherent morphological characteristics that tend to generate students' incorrect semiotic interpretations of how to use them. The work presents occurrences of mistakes repeatedly committed by undergraduate physics teachers when in the process of learning experiments for high school. The study shows that the kinds of mistakes committed by students can be explained by the affordances concept.

Key-words: Science education. Affordances. Semiotics. Experiments. 


\section{INTRODUÇÃO}

Um tipo problemático de ocorrências com graduandos de licenciatura em física da disciplina de Instrumentação para o ensino chamou nossa atenção pela persistência recorrente observada ao longo dos anos como docentes da disciplina. As ocorrências dizem respeito a determinados enganos persistentes, portanto previsíveis, cometidos por estudantes ao manipularem certos materiais durante a realização de experimentos. Em exame in loco de outras disciplinas de laboratórios didáticos, com docentes, turmas de ano e conteúdos distintos, vimos que se podiam presenciar ocorrências de naturezas semelhantes. A conclusão que se chegou dessas constatações foi que os problemas com o manuseio indevido de certos materiais não permaneciam restritos ao objetivo ou arranjo experimental, às perspectivas didáticas usadas ou vinculadas especificamente ao conteúdo ministrado, nem ao completo estranhamento da finalidade do equipamento, pois todas essas componentes variavam, sendo que, no último caso, os alunos não demonstravam dúvidas em sua utilização, ainda que estas fossem equivocadas. Aliás, as suspeitas das origens das ocorrências apontaram para influência dos materiais ou equipamentos empregados e da relação da concepção de uso que cada aluno mantinha com eles, ocasionando uma execução imprópria. Porquanto os equívocos observados não se reservaram a uma disciplina, professor, didática ou turma em particular, é também imaginável supor que eles possam se estender às genéricas aulas experimentais além das de física e para outros graus de ensino.

Em razão da ausência de um referencial teórico para interpretar tais ocorrências, à primeira vista esses fatos foram por nós testemunhados como mera curiosidade já que imaginados como erros corriqueiros dos estudantes, aparentemente banais e de fácil retificação. Em parte, esse é um motivo justificável por terem passado, até o momento, sem maior interesse ou reflexão pelos estudos da educação científica.

Todavia, os erros singulares mencionados que acometem estudantes podem ser explicados e esclarecidos mediante o que na literatura se denomina pelo termo affordance". Genericamente, affordances refere-se às características convenientes ou apropriadas que o ambiente proporciona ao animal em razão da relação interativa entre ambos. Via de regra, essa é a concepção segundo a qual os trabalhos na área de ensino aproveitam para desenvolver seus estudos no tema. Porém, neste artigo, utilizá-la-emos de maneira complementar e oposta à comumente empregada, isto é, conforme as características que o ambiente pode oferecer, mas tendo em vista gerar equívocos no aprendiz em atividades experimentais. Sob esse olhar interpretativo mais amplo, é possível utilizar o conceito de affordances para entender por que certos materiais e equipamentos são estimuladores de erros frequentes e sistemáticos em muitos aprendizes.

Diante do colocado, o artigo começa por situar em detalhes o conceito semiótico de affordances voltado para a literatura de educação científica e, em seguida, orientá-lo para explicar as ordinárias incorreções que podem acometer estudantes durante a manipulação de determinados materiais em atividades experimentais. Após essa exposição de ordem teórica, são apresentados exemplos de ocorrências que acometem frequentemente estudantes e se consegue lançar luz 
por meio do conceito de affordances. Tais exemplos decorreram de fatos ocorridos, que podem ser verificados por qualquer docente a utilizar os materiais nos contextos especificados. Na seção de fechamento, são observadas consequências da importância da tomada de consciência pelo professor do conceito de affordances e feitos os comentários finais.

\section{FUNDAMENTAC̣ÃO TEÓRICA}

\section{Objetos como signos}

Uma vertente das pesquisas em educação interessa-se por investigar e teorizar o papel das ferramentas elaboradas pelo homem que se fazem presentes nos objetos concretos e simbólicos da cultura e que dão suporte à aprendizagem. Considerações cognitivistas fundamentadas no construtivismo individual e no socioconstrutivismo mesclam-se para compreender as interações dos aprendizes entre si e com o professor, com os recursos materiais e contextos educacionais utilizados. Enquanto o construtivismo individual se volta mais para as preocupações com modelos, esquemas mentais, processos de argumentação e inferência, ou de maneira mais genérica, mecanismos gerais de pensamento, as considerações socioconstrutivistas perscrutam também a interação desses mecanismos com as ferramentas culturais (símbolos e objetos) de modo a estabelecer correlação entre linguagem e aprendizagem, e desenvolvimento e pensamento (OLIVEIRA, 1993).

Vertente da tradição socioconstrutivista, uma linha de pesquisa em educação científica ganhou impulso a partir da virada dos anos 2000 e tem se orientado com os estudos semióticos na condução de esforços para acrescentar maior qualidade à aprendizagem das ciências. Por essa linha de pesquisa, buscamse elementos teóricos na teoria dos signos que auxiliem a compreender melhor como se dão os mecanismos de apropriação pelos estudantes das representações semióticas, (DUVAL, 2004) empregadas no ensino da matemática e das ciências da natureza e suas tecnologias. Ao envolver os estudantes em atividades de produção, interpretação, transformação, coordenação e integração, em variados modos e formas representacionais desses campos do saber, criam-se condições para refinar, complementar e delimitar os conceitos matemáticos e científicos ensinados (WALDRIP; PRAIN; CAROLAN, 2010).

O conhecimento das ciências da natureza e suas tecnologias, em especial, demanda que os estudantes aprendam a selecionar e operar com representações científicas a fim de produzir não só uma interpretação ou resultado teórico corretos, mas um efeito prático desejável sobre o real, fazendo com que este último se comporte de maneira controlável e previsível. Apenas quando articula com tal competência as representações semióticas de um campo de conhecimento científico, é possível ao aprendiz conhecer, ponderar posições, realizar afirmações e, sobretudo, realizar ações sobre o real. Mas fazer referência a ações sobre o empírico que trata as ciências da natureza implica necessariamente conhecer as linguagens científicas e seus convencionados objetos ou artefatos materiais elaborados para interagir com o mundo. Aliás, ações e manipulações, aplicadas 
junto aos artefatos, constituem elas mesmas representações semióticas, haja vista que são derivadas e dirigidas para a compreensão das coisas, no caso, pela linguagem científica. $\mathrm{Na}$ realidade, toda a linguagem científica é um construto em múltiplas representações que podem se apresentar em diversas formas, tais como, na forma matemática, gráfica, diagramática, tabela, procedimentos, modelo tridimensional, simulações computacionais etc. (PRAIN; WALDRIP, 2006, p. 1844). Assim, tanto as ações corporais sobre e com os artefatos, quanto os próprios artefatos, sejam eles naturais ou artificiais, fundam-se e são relativos ao âmbito representacional, posto que lidos e operados segundo convenções da linguagem científica, que os asseguram, constituindo parte das múltiplas representações das suas respectivas culturas científicas.

A complementar essa ideia, Peirce afirma que o mundo material é um signo tanto quanto outro qualquer, pois a realidade dos fenômenos e do signo se misturam. Ele alega que o mundo não é feito de signos de um lado e coisas de outro, como se estas fossem entidades materiais e aqueles, linguagens imateriais (SANTAELLA, 2005). Peirce leva a noção de signo tão longe que não precisa apresentar plena essência de uma linguagem como palavras, desenhos, diagramas, fotos ou explicações complexas, como conceitos, teorias, definições, ideias etc., mas pode ser mera ação ou reação (p.ex., correr para alcançar um ônibus), uma simples emoção ou qualquer sentimento tal qual a qualidade vaga de sentir ternura, desejo ou raiva. O signo é aquilo que dá corpo aos pensamentos, experiências, emoções, reações, entre outros, e podem ser externados (SANTAELLA, 2005, p. 10). Consequentemente, todo signo encontra-se em alguma espécie de coisa; assim, qualquer signo é também fenômeno, é algo que aparece em nossa mente. Em particular, tudo aquilo que é material é signo, é, portanto, uma impressão que associamos a outra coisa (SANTAELLA; NÖTH, 2004, p. 88). De fato, Peirce compreende signo como composição tripla e indissociável entre três elementos: representamen (aquilo que representa), interpretante (aquilo que significa) e objeto. No que interessa destacar, na visão de Peirce, o objeto não é necessariamente algo individual, singularmente concreto, material, mas pode ser um conjunto ou coleção de coisas, evento ou ocorrência e até pode ter natureza de uma ideia abstrata. Enfim, portanto, objeto deve ser pensado como um referente que ultrapassa, mas também inclui as entidades materiais (SANTAELLA, 1995, p. 26). Ainda que o autor não confunda simplesmente objeto com estas últimas; estamos preocupados em robustecer essa reservada vinculação, pois, assim como a palavra martelo escrita ou falada é um signo em dois modos de representação diferentes (PRAIN; WALDRIP, 2006), porquanto esteja no lugar de algo, a ostentação de um martelo concreto pode igualmente estar no lugar de algo, ou seja, é capaz de representar o interpretante abstrato da classe dos martelos tal qual um som ou uma palavra, ainda que, à primeira vista, possa haver dificuldade de desvincular a singular ostentação do objeto da classe que incorpora todos esses objetos, sendo que o indicado é simplesmente um elemento da classe.

Portanto, todos os objetos privilegiados de uma cultura, assim como os artefatos científicos e composições experimentais são, pelo fato da sua simples presença, legítimas entidades semióticas, podendo ser interpretados como constituintes de uma linguagem, isto é, signos. Por implicação, como declarado, o 
mesmo se pode dizer dos procedimentos, condutas, gestos e encaminhamentos de ações práticas sobre e com eles. A propósito, todos, como entidades sígnicas, por estarem estreitamente vinculadas, mantêm seus significados estritamente associados.

Como consequência pedagógica a derivar dessa leitura semiótica, tem-se o entendimento de que compreender de forma completa o significado de um objeto científico corresponde a utilizá-lo corretamente. A demonstração das ações ou gesticulações dos estudantes mediante o manejo de objetos e artefatos científicos e suas composições experimentais possibilita àquele que ensina constatar o estado da desenvoltura intelectiva em que se encontram as elaborações dos estudantes acerca do aprendido dos conceitos científicos (LABURÚ; SILVA; ZÔMPERO, 2015). Junta-se a isso a lembrança de que essas atividades corpóreas possuem fundamental relevância cognitiva, uma vez que tomam parte e ajudam na construção das ideias (RADFORD, 2012), logo, decorre que compreender e saber fazer são ambos mecanismos que se retroalimentam continuamente.

\section{Affordance dos objetos}

Em confluência com os argumentos acima, Volli (2007) sustenta que os objetos de uso sempre foram um desafio de entendimento para a semiótica, visto a possibilidade de serem considerados e interpretados como signos constitutivos de uma linguagem. A semiótica de abordagem, com viés interpretativo, classifica os aspectos semióticos a partir da utilização dos objetos. Sua orientação fixa-se nos comportamentos dos usuários e sequências de ação praticadas diante dos objetos, dado que esses mostram potencial para sugerir sua finalidade. Por essa abordagem, um importante debate contrapôs a natureza do objeto como prótese e interface. Como prótese, procura-se entender como o objeto, por si mesmo, funciona para ampliar o papel do corpo. Como interface, perscruta-se sua capacidade para comunicar a própria função, inclusive, para usuários inexperientes. Atualmente, para Volli (2007), as diferentes abordagens semióticas partem das qualidades perceptivas e sinestésicas dos objetos para descrevê-los como autênticos processos de significação, que instigam determinadas ações e comunicam certos valores em vez de outros. Os objetos tal qual textos apresentam uma dimensão com aspectos de narrativa que os caracterizam. Isso pode ser evidenciado tendo por base o fato de que qualquer processo de significação contém mais ou menos explicitamente uma sequência de ação, de acordo com o já visto. A eficácia comunicativa dos objetos consiste em compreender como e quais características morfológicas (forma, cor, dimensão, matéria, peso, etc.) e contexto de uso comunicam a função para a qual o objeto foi concebido (VOLLI, 2007).

Dentro dessas considerações, é situado o conceito de affordances. A palavra affordances constitui um neologismo derivado da palavra inglesa afford introduzido pelo psicólogo Gibson (1986, p. 127) para descrever o que o meio ambiente oferece ou provê para o animal, seja para o bem ou para o mal. Significa relação entre um organismo e um objeto em que esse é percebido devido à relação das necessidades do organismo. Para Hammond (2010, p. 206), uma árvore tem recursos para um animal como abrigo para a chuva e o sol, ou pode ser fonte de alimento ou de proteção para se esconder de predadores. As propriedades da árvore são invariantes, 
pois permanecem as mesmas, porém é a oportunidade que provê as diferentes necessidades da mesma árvore para diferentes organismos. Segundo o autor, a essência do conceito de affordances é apontar tanto para o caminho do objeto quanto para o do organismo, de modo a ensejar circunstâncias favoráveis e restrições que se complementam. Affordances está sempre presente nas coisas, mas para os humanos precisa ser percebido para ser realizado. Em virtude disso, diferentemente dos animais servidos exclusivamente pelos instintos, para os humanos tal conceito é essencialmente cultural e subjetivo, caso contrário não é percebido.

Para Volli (2007, p. 194), affordances significa literalmente convite para o uso propiciado pela morfologia constitutiva de cada objeto que pretensamente é comunicado ao usuário. Assim, um objeto côncavo é adequado para ser contentor de algo, ou encerra uma ergonomia cujas marcas de uso previstas antecipam a postura ou a intervenção do corpo sobre ele. Todavia, assim como devido à sua morfologia, um objeto pode comunicar de modo adequado para o que vem servir, também pode fazê-lo de modo inadequado. É o caso da má projeção comunicativa de um objeto em que usuários, por exemplo, acham que deveriam girá-lo, mas que, diferentemente, deveria ser apertado ou puxado. Geralmente esse engano não depende da incapacidade do usuário, mas é, em grande parte dos casos, causado pelas qualidades perceptivas de cada objeto (VOLLI, 2007). Decorre, portanto, que as qualidades perceptivas de um objeto acionam semiose perceptiva e condicionam o agir de quem o usa, mas que o sujeito pode acabar por dar uma interpretação equivocada em razão de um projeto indevido. Daí a pertinência semiótica ou, em outras palavras, a importância da eficácia comunicativa dos objetos, que consiste nas características morfológicas e contextuais segundo as quais o usuário interage com o material, e que basicamente têm a ver com a interpretação que ele dá ao objeto.

Em suma, affordances quer significar aquilo que, na interação com o sujeito, o ambiente potencialmente proporciona, oferece ou convida a agir em razão das propriedades ou características de reconhecimento que possui, ou deveria possuir, para satisfazer certas necessidades de uso. Devido aos costumes e hábitos de experiências anteriores de convivência do agente com os objetos, aquele acaba por intuir e reconhecer as qualidades funcionais destes, determinando a interação entre ambos sem prévia explicação.

\section{Affordance na educação científica}

O conceito de affordances tornou-se influente em diversos campos de estudos, como na arquitetura, ensino, tecnologia da informação e comunicação, com os mais distintos interesses de investigação. Dentre esses interesses, citemos estudos que se voltam para a maneira como o meio ambiente pode ser emblemático e fisicamente concebido de modo a tornar-se mais natural para o usuário (NORMAN, 1998), a exemplo de uma conveniente interface para que o humano interaja com o computador do modo mais intuitivo possível. Nesse caso, a prioridade é a percepção do usuário em vez de possíveis propriedades invariantes da ferramenta (HAMMOND, 2010). Outros estudos se preocupam com o objetivo, cultura e experiências passadas do usuário que influenciam sua percepção (McGRENERE; HO, 2000; BROWN et al., 2004). Um exemplo desse 
caso é a distribuição espacial. A disposição de certas salas de escritório é planejada para dar sentido de hierarquia, uma vez que a sala da diretoria é colocada em nível mais elevado, isolada ou diferenciada na qualidade dos materiais do que aquelas dos subordinados. Outra situação habitual são as mesas compridas de reunião em que o assento da ponta é privilégio da maior autoridade.

Por sua vez, a área de educação científica se vale também de diferentes maneiras do conceito de affordances em suas investigações. Ele é empregado para examinar as características dos recursos metodológicos que permitam ou inibam o desempenho de certas atividades de ensino e atuações cognitivas em sala de aula. A destacar, os estudos que se aproveitam da estratégia de ensino em multimodos de representação (WALDRIP; PRAIN; CAROLAN, 2010) e que se servem do conceito de affordances. A título de exemplo, o trabalho de Kress et al. (2001), marcante para diversos desses estudos, procurou identificar os diferentes affordances das várias representações semióticas científicas de modo a discernir potenciais propriedades ou características de reconhecimento que carregam os diversos modos semióticos de representar o conhecimento científico e são capazes de satisfazer necessidades de aprendizagem. Cita-se, como exemplo, a investigação de Hoban e Nielsen (2014) em que a proposta de affordances é aproveitada para tratar das possibilidades convenientes que o modo de representação baseado na produção de animação via técnica de stop motion é capaz de gerar discussões em sala de aula durante o ensino de ciências. Buscou-se mostrar que a referida técnica apresenta características de reconhecimento facilitadoras para promover discussões em sala de aula. Em Fredlund, Airey e Linder (2012) affordances é empregado como papel comparativo que diferentes representações semióticas de física (p. ex., representação das ondas no papel como raios versus frente de ondas) proporcionam para produzir engajamento comunicativo em sala de aula e, com isso, compartilhar o conhecimento estudado. No ensino de química, Kozoma (2003) pesquisa as características das múltiplas representações e os affordances cognitivos e sociais que dão suporte à compreensão científica nessa matéria. Seus resultados sugerem que o uso de um ambiente simbólico de química com atividades de investigação de laboratório pode prover affordances para uma construção compartilhada de conhecimentos científicos. Como apontamento final, na mesma direção, Wu e Puntambekar (2012, p. 756) examinam a maneira como diferentes e desejáveis affordances, ligados às múltiplas representações, podem ser integrados para estimular e facilitar processos científicos do tipo formular questionamentos, planejar investigações, analisar dados, construir explicações etc.

Como se depreende desses e de outros trabalhos, eles se valem da ideia de affordances para identificar as possibilidades que as inerentes características das estratégias de ensino ou de formas representacionais oportunizam para que determinados fins instrucionais sejam atendidos.

\section{AFFORDANCES NEGATIVOS DOS INSTRUMENTOS CIENTÍFICOS}

Considerada a questão do início do trabalho, nesta seção relatamos a ocorrência de quatro casos de uso equivocado de instrumentos científicos que, 
em seguida, serão interpretados à luz do conceito de affordances. Os três primeiros casos referem-se a aparelhos que devem ser operados diretamente pelos alunos e que participam como instrumentos auxiliares ou principal equipamento de experimentos quantitativos. O último caso trata-se de um aparelho usado em demonstrações. Normalmente, é operado por um instrutor enquanto os estudantes apenas observam o fenômeno revelado.

Como adiantado na Introdução, todos os casos descritos se originaram da observação direta das ações, questionamentos ou comentários dos estudantes no momento da manipulação com os equipamentos dos três primeiros casos, ou de seus comentários ao observar o fenômeno do último caso. Cada situação aconteceu em uma aula independente das demais durante a disciplina de Instrumentação para o ensino de física da licenciatura, em atividades experimentais distintas, desempenhadas por diferentes alunos.

\section{Caso 1 - Equipamento para transformação isotérmica em gases}

Um equipamento para estudar transformações isotérmicas em gases utiliza uma seringa de vidro de $20 \mathrm{ml}$. O objetivo é fazer com que o estudante estabeleça a relação da pressão com o volume do gás contido na seringa, ou seja, a lei de Boyle-Mariotte. Na cabeça do êmbolo da seringa, é colada uma chapa de madeira retangular com a finalidade de suportar tijolos para variar a pressão do gás. Para o gás ficar contido dentro da seringa, sua agulha é tapada com uma rolha de borracha, e o êmbolo é lubrificado com óleo de câmbio de carro para evitar vazamentos. A seringa é suportada em pé por uma mufa presa a um suporte universal.

Constatação: para realizar a medida da pressão dos tijolos sobre o gás, vários alunos se servem frequentemente da área da madeira e não da correta área do êmbolo que está em contado direto com o gás.

\section{Caso 2 - Transferidor usado na medição da dilatação linear de sólidos}

Um experimento didático para estudar a dilatação linear de sólidos consiste basicamente de um de cano reto de metal deitado sobre a beirada de uma mesa que atinge sua quina. $\mathrm{Na}$ entrada do cano do lado oposto à quina da mesa e que permanece afixada, injeta-se vapor de água quente. A saída de vapor na ponta do tubo na quina da mesa permanece livre para o tubo poder dilatar. Em razão do valor da dilatação ser muito pequeno, embaixo da ponta livre coloca-se um alfinete deitado perpendicular ao tubo que gira na medida em que ocorre a dilatação. Para o giro do alfinete ser visível e ser possível medi-lo, seu corpo é transpassado por um fino canudinho que serve de ponteiro para medir o ângulo por meio do qual é possível indiretamente determinar a variação do comprimento dilatado. Para a obtenção do ângulo variado pelo alfinete-canudinho, é necessário que se coloque o centro do transferidor na cabeça do alfinete e meça-se a posição do canudinho na escala do transferidor. Todavia, certas marcas de transferidores possuem a linha base $0^{\circ}-180^{\circ}$ do gabarito impressa alguns milímetros abaixo do limite do plástico, como mostra a figura 1. Assim, para que a medida de ângulos seja perfeitamente realizada, é necessário que o centro de giro do ângulo a se medir, dado pelo centro 
da cabeça do alfinete, fique exatamente no ponto central do gabarito (cruzamento da linha $0^{\circ}-180^{\circ}$ com a linha $90^{\circ}$ na figura 1$)$.

Constatação: a medida do giro do ponteiro é realizada com frequência por vários estudantes, colocando a cabeça do alfinete sobre o limite externo da parte plástica superior do transferidor e não no centro do gabarito que se encontra um pouco abaixo, como deveria ser o emprego correto do instrumento.

\section{Figura 1}

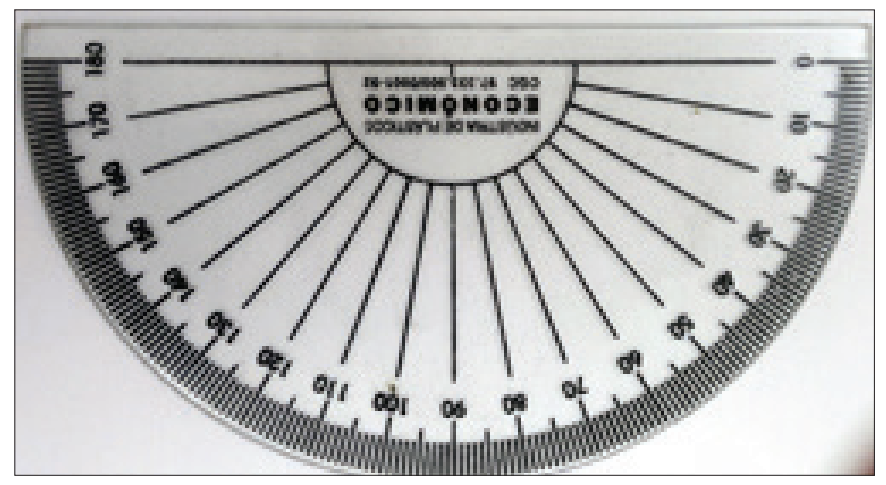

\section{Caso 3 - Experimento do empuxo}

Em um experimento para a determinação do empuxo de um objeto flutuante, é necessário que se meça o volume de líquido deslocado pelo objeto. Para a realização do experimento, os estudantes contavam, além de outros materiais, com uma pequena seringa hipodérmica de $10 \mathrm{ml}$ com seu bico tapado e sem o êmbolo. Sua finalidade era servir de proveta e medir, com precisão, o volume de líquido deslocado, cujo valor ultrapassava a capacidade de $10 \mathrm{ml}$ da seringa. Além disso, também contavam com um Becker de $80 \mathrm{ml}$ que tinha tão somente a função de recipiente para captar a água vertida do volume deslocado pelo objeto, e que deveria ser posteriormente medido com precisão por meio da seringa (proveta) de $10 \mathrm{ml}$. O Becker era posicionado abaixo de outro recipiente cheio d'água até seu limite, em que o objeto em estudo era vagorosamente afundado até flutuar. A título de esclarecimento, é importante frisar que ainda que o Becker possuísse capacidade volumétrica para medir de uma só vez o volume de líquido deslocado obtido (pouco mais de $10 \mathrm{ml}$ ), facilitando o procedimento se comparado com o uso da seringa-proveta, pois esta apresenta o inconveniente de ser preenchida mais de uma vez por possuir capacidade volumétrica limitada $(10 \mathrm{ml})$, contudo, a escala do Becker é muito grosseira, ou seja, é demasiadamente imprecisa para efetuar a medição do volume de líquido deslocado. Portanto, a consequência de usar diretamente o Becker como instrumento de medida é a obtenção de dados grosseiros e inconclusivos, visto que o valor do volume deslocado é pequeno no experimento e somente a seringa-proveta é capaz de fornecer resultados precisos e satisfatórios dada as especificidades dos materiais empregados.

Constatação: se não advertidos previamente, quase sempre os alunos 
priorizam o impreciso Becker em detrimento da seringa-proveta como instrumento de medição do volume de líquido deslocado.

\section{Caso 4 - Câmara da neblina}

A câmara de neblina é um detector de partículas subatômicas que permite observar as trajetórias dessas partículas. Versões didáticas da câmara de neblina de expansão possuem uma membrana elástica com a finalidade de provocar a expansão do gás para torná-lo supersaturado. Não obstante, como esse procedimento é rápido, as trajetórias das partículas são vistas se curvando para o fundo da câmara, como consequência da expansão do gás sugado para baixo pela membrana localizada no fundo do equipamento. Isso contraria a condição de trajetória reta que deveria ser o caso de partículas livres.

Constatação: por causa disso, há alunos que comentam que as partículas estão sendo atraídas pelo campo gravitacional ou desviadas para baixo por outro campo qualquer.

\section{Interpretação dos casos a partir de uma leitura dos affordances}

No caso 1, a plataforma de madeira é saliente no equipamento, visto ser grande e externa e, na medida em que mantém contato direto com os tijolos para suportá-los, tende a induzir o uso de sua área para o cálculo da pressão do gás que a força-peso do tijolo exerce. Tais fatores visuais naturalmente direcionam a atenção do estudante/usuário para a área da madeira, em vez da pequena área do êmbolo que se encontra escamoteada dentro da seringa, logo, pouco evidente, para ser empregada para a determinação da pressão. Desse modo, sem uma reflexão mais rigorosa, a área da madeira do equipamento exerce forte atração para aquele que manuseia o aparelho, mas que, se empregada, torna o experimento errado, pois a pressão é incorretamente determinada.

No caso 2, a escolha de um transferidor com características iguais às da figura 1 (gabarito abaixo do limite do plástico), seduz o usuário a empregá-lo junto à parte superior do plástico, logo, fora do gabarito. O motivo disso está na facilidade de manipular o instrumento dessa maneira para ajustá-lo abaixo do alfinete. Há, ainda, a conveniência de a linha da borda da mesa sobre a qual o alfinete se deita ser usada para auxiliar o alinhamento do transferidor para realizar o zeramento inicial do ponteiro para daí tirar a medida final. Procedendo dessa maneira, a medida pode ser obtida aparentemente sem maiores transtornos, ainda que incorreta. Para comparar, o procedimento certo para usar o transferidor é mais laborioso. Seu centro de medida precisa ser ajustado com precisão no centro da cabeça do alfinete, segurando o transferidor livre no espaço, com as mãos à sua frente, além de que há a inconveniência de mantê-lo constantemente alinhado com a borda da mesa para assegurar uma referência entre o zeramento e o ângulo final atingido.

No caso 3, o uso preferencial pelos estudantes do inapropriado Becker de $80 \mathrm{ml}$, já que sua utilização fornece uma medida de qualidade imprecisa se comparada à fornecida pela seringa-proveta, pode ser justificada por três motivos. Antes de tudo, porém, é preciso excluir dessas justificativas a despreocupação do 
estudante com a necessidade de precisão na retirada das medidas, e que o levaria, por esse critério, a escolher a seringa-proveta por simples comparação da precisão dos instrumentos. Tal explicação, apesar de fundamental, encontra-se fora do âmbito de uma leitura à luz do conceito de affordances. Mas tendo essa leitura em consideração, entende-se a opção pelo Becker de $80 \mathrm{ml}$, primeiramente, por ele já estar sendo manuseado como recipiente para depósito do líquido vertido do qual vai ser determinado o volume. Usá-lo, portanto, como instrumento de medida vem como consequência imediata de estender o seu emprego de simples recipiente para também servir de medidor, o que é conveniente, pois reduz procedimentos. Outra segunda conveniência é se poder medir o líquido de uma só vez, graças à morfologia do Becker oferecer maior capacidade volumétrica para a quantidade medida do que a da seringa-proveta. Esta última apresenta o inconveniente de necessitar que sejam repetidas medidas parciais para que somadas se obtenha, com precisão, o resultado final do volume total. Uma terceira e última explicação vem do atributo do Becker já possuir escala para realizar medidas de volume. Esta é um convite para que o instrumento seja empregado para determinar a quantidade de líquido, lembrando, mais uma vez, que os estudantes normalmente não se preocupam com a questão da precisão dos instrumentos. Assim, caso a captação do volume de líquido derramado fosse feita em um recipiente que não tivesse escala, como um simples copo, por exemplo, a seringa-proveta seria o único equipamento disponível e somente por meio dela se poderia realizar essa medida. Por conseguinte, as três justificativas conjugadas imputam ao affordances do Becker o motivo pela frequência de seu indevido uso em preferência ao da seringa-proveta, que seria o instrumento certo a ser empregado no experimento.

No caso 4, as características de construção da câmara de neblina de expansão especificada produzem o efeito colateral que vai além de mostrar as trajetórias das partículas. Como as trajetórias das partículas são sugadas para baixo, em razão da expansão do gás realizada, elas deixam de ser retilíneas e aparecem como curvas, dando a aparente sensação de que as partículas são desviadas para baixo. Assim, em razão dos affordances desse aparelho, há indução incorreta dessa conclusão à qual se é levado por causa de suas características constitutivas.

Os casos relatados mostram exemplos vivenciados do emprego desvirtuado das finalidades para as quais foram inicialmente elaborados os equipamentos e que são capazes de ser explicados a partir do ponto de vista do conceito de affordances. Depreende-se do exposto na seção teórica que, em razão dos affordances dos equipamentos utilizados, é recorrente notar, em sala de aula, estudantes se equivocando de forma semelhante quando usam ou interagem de alguma forma com esses equipamentos. Em virtude das características morfológicas particulares, tais equipamentos convidam seus usuários estudantes para o uso incorreto deles, fazendo, portanto, com que sejam operados erradamente em razão de interpretação equivocada de seus atributos.

\section{COMENTÁRIOS FINAIS E CONCLUSÃO}

Buscou-se abarcar casos problemáticos e distintos de utilização de 
materiais pelos estudantes em atividades de laboratório didático e mostrar que essas situações podem ser interpretadas à luz do conceito de affordances. Como se viu, as situações procedimentais apresentaram características variadas. Elas contaram com uma demonstração que emprega um aprimorado instrumento de câmara de neblina, em que os estudantes têm uma atitude observacional passiva em relação ao equipamento; contaram também com materiais muito simples sobre os quais eles operam diretamente, como no caso do transferidor e Becker, ou não tão simples como o equipamento adaptado para estudar transformações em gases.

Ainda que algumas problemáticas apontadas possam ser classificadas como cognitivamente modestas, evitá-las por advertência prévia do professor ou readequar os materiais com affordances, que convidem ao manuseio correto, talvez possam ser caminhos que o professor opte por seguir. Por esses caminhos, se é capaz de, por exemplo, usar uma câmara de neblina de difusão cujo arranjo estrutural evitaria o efeito apontado. Ou trocar o Becker para captação do líquido por um simples copo sem escala volumétrica, como já fora antecipado, ou, quem sabe, substituir o transferidor por outra marca para contornar e obliterar o problema visto. Por outro lado, em vez de o professor adequar materiais e instrumentos para afastar a geração de prováveis equívocos para os alunos, ou fazer advertências para evitar enganos antes que aconteçam, talvez seja cognitivamente mais produtivo problematizar os constatados affordances negativos via uma abordagem instrucional que incentive uma aprendizagem com maior significação. Para tanto, um professor deve ser capaz de antecipar para a classe os problemas que irão ocorrer, direcionando, dentro de um planejamento prévio, o enfrentamento crítico desses. Em outras palavras, uma aprendizagem sob esse enfoque permite que o professor, conhecendo ou identificando os affordances negativos dos objetos, estimule a discussão dos equívocos intrínsecos que esses materiais e instrumentos possam vir a trazer ao entendimento dos estudantes, evitando assim que se propaguem no decorrer da atividade, prejudicando-a. Um maneira de efetivar isso seria estabelecer um debate a respeito do procedimento necessário para medir a pressão do gás no caso 1, tendo como foco a opção da área a ser considerada. Nessa perspectiva, um ensino reflexivo e significativo, contraposto a um ensino autômato e informativo, logo, superficial, poderia ser conduzido ou efetivado. Por detrás do que se está a sugerir, encontrase o princípio do psicopedagogo Édouard Claparède que, resumidamente, afirma que quanto mais suavemente utilizarmos uma relação em ação menos teremos consciência dessa relação; a consciência que tomamos do que estamos fazendo varia na proporção direta das dificuldades para nos adaptarmos a uma situação.

Ainda que reais os exemplos apresentados, seus destaques no trabalho tiveram papel ilustrativo e de contribuição para que os professores fiquem atentos para ocorrências que possam vir a acontecer com outros materiais em outras situações. Por isso, extrapolar as investigações a outros graus de ensino e matérias de ciências deve mostrar a natureza geral e fecunda do conceito de affordances, considerada a problemática aqui especificada, sendo até mesmo útil para pontuar casos corriqueiros que se disseminam nas aulas práticas de ciências e costumam passar despercebidos.

Por fim, espera-se que o estudo contribua para que os professores das ciências se tornem mais capacitados para compreender um tipo de recalcitrância de aprendizagem que acontece durante os momentos instrucionais que empregam 
atividades práticas experimentais e, por consequência, possam tomar decisões que possibilitem que esses obstáculos sejam ultrapassados pelos alunos.

\section{NOTAS}

${ }^{1}$ Bolsista do CNPq-Brasil.

\section{REFERÊNCIAS}

BROWN, J.; STILLMAN, G.; HERBERT, S. Can the notion of affordances be of use in the design of a technology enriched Mathematics curriculum? In: I. PUTT, R.; FARAGHER; McLEAM. N (Eds) Proceedings of the 27th Annual Conference of the Mathematics Education Research Group of Australasia, Sydney, MERGA, v. 1, p. 119-126, 2004.

DUVAL, R. Semiosis y pensamiento humano: registros semióticos y aprendizajes intelectualesSantiago de Cali: Universidad del Vale, Instituto de Educación y Pedagogía, 2004.

FREDLUND, T.; AIREY, J.; LINDER, C. Exploring the role of physics representations: an illustrative example from students sharing knowledge about refraction. European Journal of Physics, v. 33, p. 657-666, 2012.

GIBSON, J. The ecological approach to visual perception. New York: Lawrence Erlbaum Associates, 1986.

HAMMOND, M. What is an affordance and can it help us understand the use of ICT in education? Education and Information Technologies, v. 15, p. 205-217, 2010.

HOBAN, G.; NIELSEN, W. Creating a narrated stop-motion animation to explain science: the affordances of "slowmotion" for generating discussion, Teaching and Teacher Education, v. 42, p. 68-78, 2014.

KOZMA, R. The material features of multiple representations and their cognitive and social affordances for science understanding. Learning and Instruction, v. 13, p. 205-226, 2003.

KRESS, G.; JEWITT, C.; OGBORN, J.; TSATSARELIS, C. Multimodal teaching and learning: The rhetorics of the science classroom. London: Continuum, 2001.

LABURÚ, C. E.; SILVA, O. H. M.; ZÔMPERO, A. F. Significados de eletrostática interpretados por meio da gesticulação de estudantes. Ciência \& Educação, v. 21, n. 4, p. 851-867, 2015.

McGRENERE, J.; HO, W. Affordances: clarifying and evolving a concept. In: Proceedings of Graphic Interface 2000. Montreal, May, p. 179-186, 2000.

NORMAN, D. The psychology of everyday things. New York: Basic Books, 1998.

OLIVEIRA, M. K. Vygotsky, aprendizado e desenvolvimento. Um processo sócio-histórico. São Paulo: Editora Scipione, 1993. (Série Pensamento e Ação no Magistéro)

PRAIN, V.; WALDRIP, B. An exploratory study of teachers' and students' use of multi-modal representations of concepts in primary science. International Journal of Science Education, v. 28, n. 15, p. 1843-1866, 2006.

RADFORD, L. On the cognitive, epistemic, and ontological roles of artefacts. In: G. GUEUDET, G.; PEPIN, B.; TROUCHE, L. (Eds.). From test to "lived" resources. New York: Springer, 2012. p. 238-288.

SANTAELLA, L. A teoria geral dos signos: semiose e autogeração. São Paulo: Ática, 1995.

SANTAELLA, L. Semiótica aplicada. São Paulo: Thomson, 2005.

SANTAELHA, L.; NÖTH, W. Comunicação \& semiótica. São Paulo: Hacker Editores2004. 248 p. 
WALDRIP, B.; PRAIN, V.; CAROLAN, J. Using multi-modal representations to improve learning in junior secondary science. Research in Science Education, v. 40, p. 65-80, 2010.

WU, H-K.; PUNTAMBEKAR, S. Pedagogical Affordances of Multiple External Representations in Scientific Processes. Journal of Science Educational Technology, v. 21, p. 754-767, 2012.

VOLLI, U. Manual de semiótica.2. ed. São Paulo: Edições Loyola, 2007.

Submetido em 29/02/2016

Aprovado em 24/04/2017

Contato:

Carlos Eduardo Laburú

Universidade Estadual de Londrina

Departamento de Física, CCE

Rodovia Celso Garcia Cid Pr 445 km 380 Campus Universitário

Caixa Postal 10.011

CEP 86.057-970

Londrina $|\mathrm{PR}|$ Brasil 